University of Nebraska - Lincoln

DigitalCommons@University of Nebraska - Lincoln

$9-1-1996$

\title{
High coercivity SmFeSiC films fabricated by multilayer sputtering
}

S.Y. Zhang

University of Nebraska - Lincoln

Z.S. Shan

University of Nebraska - Lincoln

Yi Liu

University of Nebraska-Lincoln, yliu@unl.edu

David J. Sellmyer

University of Nebraska-Lincoln, dsellmyer@unl.edu

Follow this and additional works at: https://digitalcommons.unl.edu/physicssellmyer

Part of the Physics Commons

Zhang, S.Y.; Shan, Z.S.; Liu, Yi; and Sellmyer, David J., "High coercivity SmFeSiC films fabricated by multilayer sputtering" (1996). David Sellmyer Publications. 76.

https://digitalcommons.unl.edu/physicssellmyer/76

This Article is brought to you for free and open access by the Research Papers in Physics and Astronomy at DigitalCommons@University of Nebraska - Lincoln. It has been accepted for inclusion in David Sellmyer Publications by an authorized administrator of DigitalCommons@University of Nebraska - Lincoln. 


\title{
High Coercivity SmFeSiC Films Fabricated by Multilayer Sputtering
}

\author{
S.Y. Zhang ${ }^{(1)}$, Z.S. Shan ${ }^{(1)}$, Y. Liu ${ }^{(2)}$, D.J. Sellmyer ${ }^{(1)}$ \\ Center for Materials Research and Analysis \\ University of Nebraska, Lincoln, Nebraska 68588-0113 \\ T.Y. Zhao, J.G. Zhao, B.G. Shen \\ Institute of Physics, Chinese Academy of Sciences, Beijing, 100080
}

\begin{abstract}
SmFeSiC thin films have been obtained by sputtering $\mathrm{SmFe} / \mathrm{C}(\mathrm{Si})$ multilayers with a $\mathrm{Ta}$ underlayer on Si substrates and subsequently annealing at $700^{\circ} \mathrm{C}$. The coercivity of the SmFeSiC films strongly depends on the sputtering and annealing conditions. The influence of the thickness of the Ta underlayer, the thickness ratio of $\mathrm{SmFe}$ to $\mathrm{C}(\mathrm{Si})$, the argon pressure and heat treatment In- plane coercivities up to $7.2 \mathrm{kOe}$ and squareness of 0.94 were obtained.
\end{abstract}

\section{INTRODUCTION}

Permanent-magnet films such as $\operatorname{CoCrX} \quad(\mathrm{X}=$ Ta,Pt,Ni...) [1], SmCo [2], NdFeB [3], Sm(Fe,T) ( $\mathrm{T}=$ $\mathrm{Ti}, \mathrm{V})$ [4], and SmFeN [5] have been attracting much attention for applications as magnetic recording media, bias magnets and exchange-spring materials. The intermetallic compounds $\mathrm{Sm}_{2} \mathrm{Fe}_{17} \mathrm{C}_{\mathrm{y}}$ have intrinsic magnetic properties similar to $\mathrm{Sm}_{2} \mathrm{Fe}_{17} \mathrm{~N}_{\mathrm{x}}$. However, until now studies have been concentrated on bulk $\mathrm{Sm}_{2} \mathrm{Fe}_{17} \mathrm{C}_{\mathrm{y}}$ materials. No work on $\mathrm{SmFeC}$ films has been reported. The thin-film structure provides an additional synthetic route, a better uniformity and certain device applications. We found $\mathrm{SmFeC}$ films with high coercivity are difficult to synthesize from only three elements. It was reported that some fourth elements, such as $\mathrm{Si}, \mathrm{Ga}$ and $\mathrm{Al}$, that partially replace $\mathrm{Fe}$, stabilize the structure of 2:17-type carbides [6,7]. In this paper we report the successful preparation of $\mathrm{SmFeSiC}$. films with coercivity as high as $7.2 \mathrm{kOe}$, and systematic studies of the effects of the process variables on the film properties.

\section{EXPERIMENTS}

SmFeSiC films were prepared by dc magnetron sputtering. First, $\mathrm{SmFe} / \mathrm{C}(\mathrm{Si})$ multilayer films were deposited at room temperature on Si substrates with Ta underlayer and overcoating, then annealed in vacuum of $2 \times 10^{-6}$ Torr. A composite $\mathrm{Sm}_{2} \mathrm{Fe}_{17}(\mathrm{Sm})$ alloy target and a composite graphite( $\mathrm{Si}$ ) target were used. The chamber base pressure was about $4 \times 10^{-7}$ Torr. The deposition rates

(1) Behlen Laboratory of Physics

(2) Department of Mechanical Engineering. were about $9 \dot{A} / \mathrm{sec}$ for $\mathrm{Sm}_{2} \mathrm{Fe}_{17}$ and about $2 \dot{A} / \mathrm{sec}$ for $\mathrm{C}(\mathrm{Si})$. The sputtering pressures ranged from 5 to $30 \mathrm{mT}$ of argon gas.

The magnetic properties of the films were measured by an alternating gradient force magnetometer with a maximum field of $14 \mathrm{kOe}$. Compositions were measured by a EDX spectrometer, and the structural properties were examined by $\mathrm{X}$-ray diffraction $(\mathrm{CuK} \alpha)$, and transmission electron microscopy (TEM).

\section{RESULTS AND DISCUSSION}

The intrinsic coercivity of SmFeSiC thin films was studied by systematically varying the sputtering and heat treatment parameters in order to find an optimal set of variables that yields a maximum in coercivity. Figure 1 shows that for a given thickness of single $\operatorname{SmFe}(37 \AA)$ layer, and a given argon pressure $(10 \mathrm{mT})$, the coercivity for the films annealed at $700^{\circ} \mathrm{C}$ for $5 \mathrm{~min}$ increases with increasing single $\mathrm{C}(\mathrm{Si})$ layer thickness, reaches the maximum value at $10 \AA$, and then decreases with increasing single $\mathrm{C}(\mathrm{Si})$ layer thickness. However, nearly the same coercivities are obtained for the samples with a given

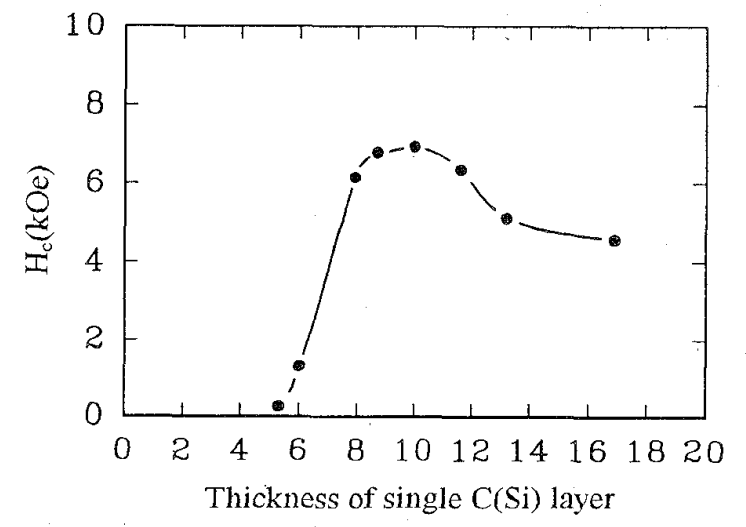

Fig. 1 Coercivity vs. thickness of single $\mathrm{C}$ (Si) layer for $\mathrm{Si} / \mathrm{Ta}(1000 \AA) /[\mathrm{SmFe}(37 \AA) / \mathrm{C}(\mathrm{Si})(\mathrm{X} \AA)] \times 58 / \mathrm{Ta}(200 \AA)$, where " $x$ 58" denotes the no. of bilayers and this notation is used hereafter, films after annealing at $700^{\circ} \mathrm{C}$ for $5 \mathrm{~min}$. 


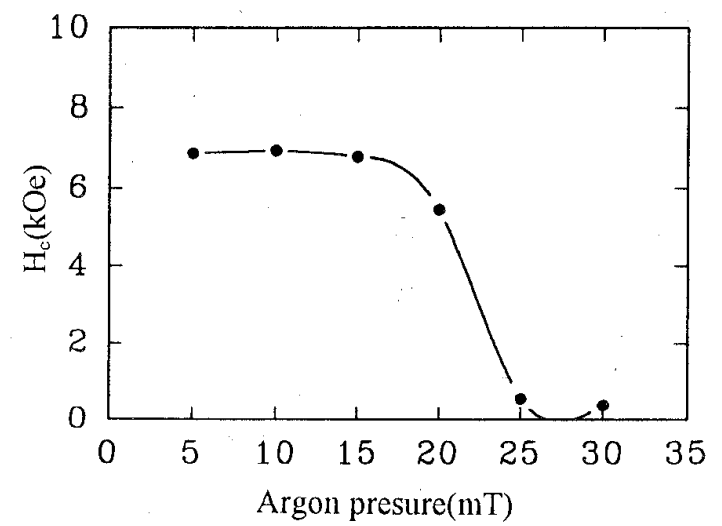

Fig. 2 Coercivity vs. argon pressure for $\mathrm{Si} / \mathrm{Ta}(1000 \AA) /[\mathrm{SmFe}(100 \AA) / \mathrm{C}(\mathrm{Si})(27 \AA)] \times 21 / \mathrm{T} 2(200 \AA)$ films after annealing at $700^{\circ} \mathrm{C}$ for $5 \mathrm{~min}$.

ratio of $\mathrm{SmFe} / \mathrm{C}(\mathrm{Si})=3.7$ prepared at $5-15 \mathrm{mT}$ argon pressure (Fig. 2), above which the coercivity decreases

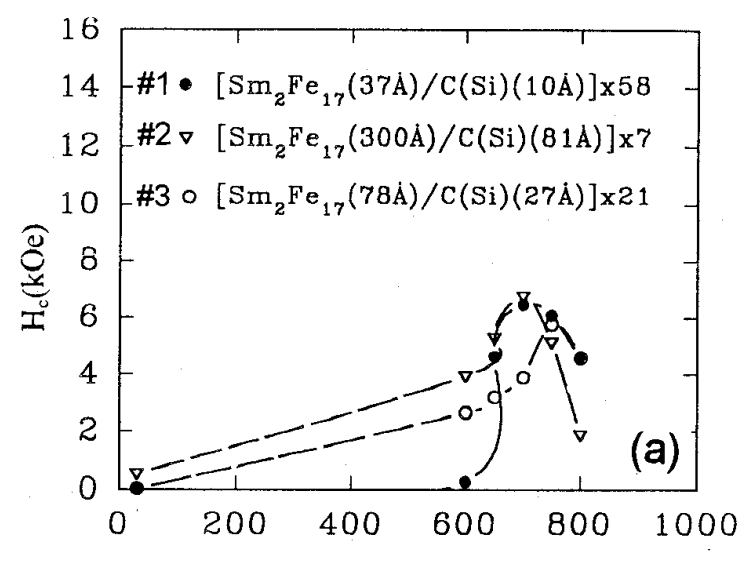

Annealing temperature $\left({ }^{\circ} \mathrm{C}\right)$

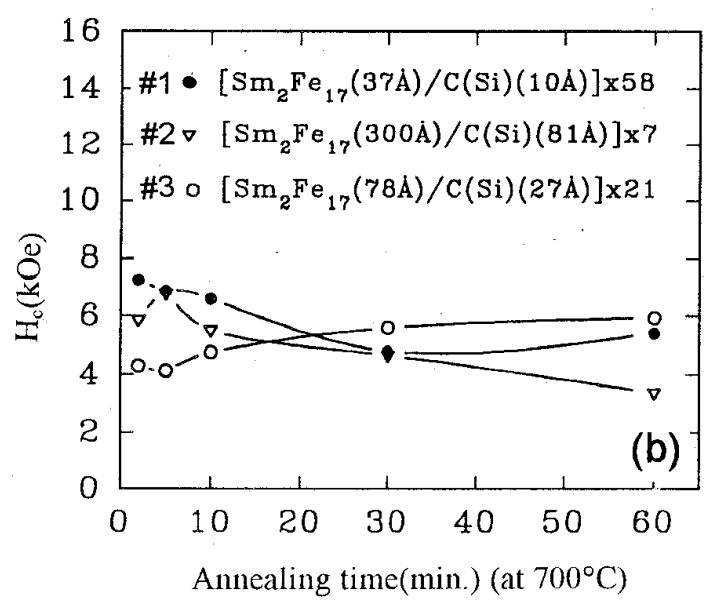

Fig. 3 Coercivity vs. annealing temperature and time for $\mathrm{Si} / \mathrm{Ta}(1000 \AA) /[\mathrm{SmFe} / \mathrm{C}(\mathrm{Si})] / \mathrm{Ta}(200 \AA)$ films.

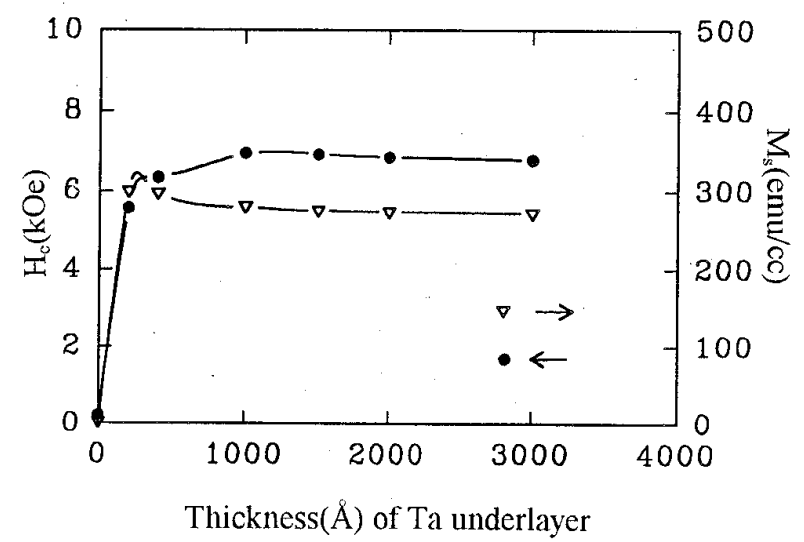

Fig. 4 Coercivity and magnetization vs. Ta underlayer thickness for $\mathrm{Si} / \mathrm{Ta} /[\mathrm{SmFe}(100 \dot{A}) / \mathrm{C}(\mathrm{Si})$ $(27 \AA)] \times 21 / \mathrm{Ta}(200 \AA)$ films after annealing at $700^{\circ} \mathrm{C}$ for 5 min.

rapidly with increasing the argon pressure. It has been shown that the argon pressure can affect the microstructure of the similar films strongly[8].

Figure 3 illustrates coercivity as a function of annealing temperature and time. It is seen that annealing temperature has important effects on the coercivity. The coercivity for samples \#1 and \#2, which have the same thickness ratio of $\mathrm{SmFe} / \mathrm{C}(\mathrm{Si})=3.7$ and same total multilayer thickness but different single layer thickness, reaches the same maximum value at $700^{\circ} \mathrm{C}(\mathrm{Fig} .3 \mathrm{a})$. For the sample \#3 which has the thickness ratio of $\mathrm{Sm} / \mathrm{Fe} / \mathrm{C}(\mathrm{Si})=2.9$, the coercivity reaches the maximum value at $750^{\circ} \mathrm{C}$ (Fig.3a). The annealing time does not affect the coercivity greatly (Fig. $3 \mathrm{~b}$ ). These optimal values of the ratio of $\mathrm{SmFe} / \mathrm{C}(\mathrm{Si})=3.7,10 \mathrm{mT}$ argon pressure, and annealing at $700^{\circ} \mathrm{C}$ for $5 \mathrm{~min}$ for $\mathrm{SmFeSiC}$ on $\mathrm{Si} / \mathrm{Ta}(1000 \AA)$, were used for further studies.

Figure 4 shows the dependence of coercivity and saturation magnetization for SmFeSiC films on $\mathrm{Ta}$ underlayer thickness. The coercivity and magnetization increase very rapidly with increasing thickness of Ta up to $400 \AA$ and $200 \AA$ respectively, and then remain nearly constant. These behaviors are similar to other alloy systems[9]. It was reported that the grain size and texture of the magnetic layer is controlled by the presence of $\mathrm{Cr}$ underlayer $[8,9,10]$. Consequently the magnetic properties of these films is improved as shown for $\mathrm{CoCrPt}[10]$ and SmCo[8]. X-ray diffraction patterns show that the Ta underlayer on Si substrates has a $<002\rangle$ texture after deposition at room temperature.

The composition of optimal films detected by EDX is $\mathrm{Sm}_{2} \mathrm{Fe}_{12} \mathrm{Si}_{2} \mathrm{C}_{\mathrm{x}}$. X-ray diffraction studies of $\mathrm{SmFeSiC}$ layers have been performed and no characteristic crystalline peaks were observed. This may be attributed to the fact that the crystallite size is rather small and the films are fairly thin; thus the films are in the so-called $x$-ray 
amorphous states. High resolution TEM image shows the grain size is in the range of $10-20 \mathrm{~nm}$ and no amorphous

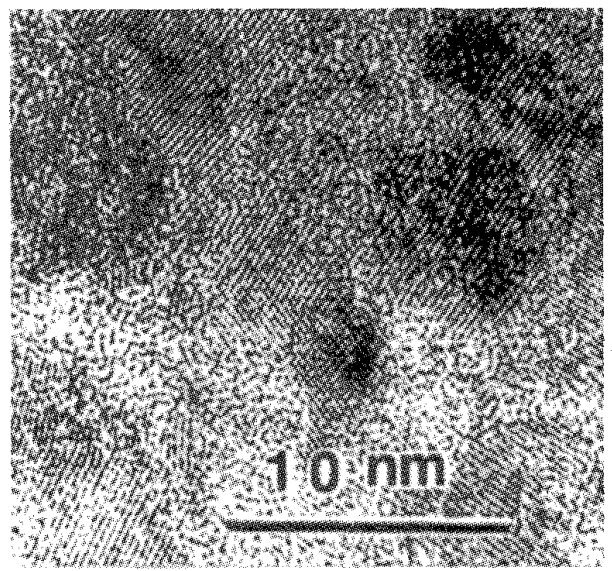

Fig. 5. High resolution TEM image for $\mathrm{Si} / \mathrm{Ta}(1000 \AA) /[\mathrm{SmFe}(37 \AA) / \mathrm{C}(\mathrm{Si})(10 \AA) \times 58 / \mathrm{Ta}(200 \AA)$ films after annealing at $700^{\circ} \mathrm{C}$ for $5 \mathrm{~min}$.

phase was detected (Fig. 5). Several possible phases around the $\mathrm{Fe}(\mathrm{Si}) / \mathrm{Sm}$ atomic ratio of 7 are $\mathrm{Cu}_{7} \mathrm{~Tb}$ and $\mathrm{Zn}_{17} \mathrm{Th}_{2}$, which are related to each other by structure transformation[10]. However, the electron diffraction ring pattern does not show an acceptable match to the $\mathrm{Cu}_{7} \mathrm{~Tb}$ structure or the $Z_{n_{2}} T_{17}$ structure. The analysis of the crystal structure of the magnetic phase is in progress by convergent beam electron diffraction and HREM.

The typical hysteresis loop of SmFeSiC films is shown in Fig. 6. SmFeSiC film has an in-plane coercivity of $7.2 \mathrm{kOe}$, however the $\mathrm{SmFe}$ film with same thickness of magnetic layer as $\mathrm{SmFeSiC}$ made by same condition has a coercivity of about $2 \mathrm{kOe}$. The squareness of in-plane loops for SmFeSiC is 0.94 , which is better than those of $\mathrm{SmFeN}$ films[5]. The hysteresis loops for both in-plane and perpen-

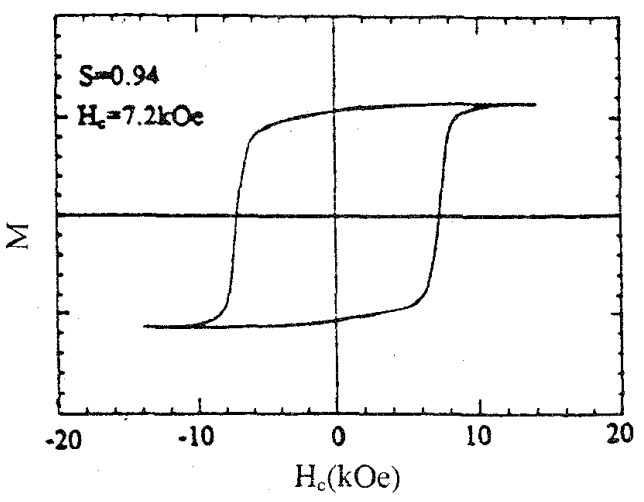

Fig. 6 Hysteresis loop of the sample shown in Fig. 5. dicular loops are similar, which indicates that $\mathrm{SmFeSiC}$ film made by this method is isotropic.

The results reported here show that high coercivity up to $7.2 \mathrm{kOe}$ can be achieved in SmFeSiC thin films. Studies on the role of the $\mathrm{Ta}$ underlayer, and the correlation of the coercivity with the microstructure in $\mathrm{SmFeSiC}$ films are in progress.

\section{ACKNOWLEDGMENTS}

We would like to thank S.H. Liou, F. Foong and M.J. $\mathrm{Yu}$ for their assistance and helpful discussions. This work at the University of Nebraska was supported by NSF DMR-9222276, DOE DEFG-86ER45262 and the Center for Materials Research and Analysis.

\section{REFERENCES}

[1] R.D. Fisher, J.C. Allan, and J.I. Pressesky, "Magnetic Properties and Longitudinal Recording Performance of Corrosion-Resistant Alloy Films," IEEE Trans. Magn., Vol. 22, pp. 352-354, 1986

[2] E.M.T. Velu and D.N. Lambeth, "High Density Recording on $\mathrm{SmCo} / \mathrm{Cr}$ Thin Film Media," IEEE Trans. Magn., Vol. 28, pp. 3249-3254, 1992.

[3] K.D. Aylesworth, Z.R. Zhao, D.J. Sellmyer, "Growth and Control of the Microstructure and Magnetic Properties of Sputtered $\mathrm{Nd}_{2} \mathrm{Fe}_{14} \mathrm{~B}$ Films and Multilayers," J. Magn. Magn. Mater., Vol. 82, pp. 48-56, 1989.

[4] T.D. Cheung, Wickramasekara, and F.J. Cadieu, "Large In-Plane Anisotropy in Amorphous Sm-Co and (Sm+Ti) Fe Films," J. Appl. Phys., Vol. 57, pp. 3598-3600, 1985 .

[5] D. Wang, S.H. Liou, P. He, D.J. Sellmyer, G.C. Hadjipanayis, and Y. Zhang, "SmFe $e_{12}$ and $\mathrm{SmFe}_{12} \mathrm{~N}_{\mathrm{x}}$ Films Fabricated by Sputtering," J. Magn. Magn. Mater., Vol. 124, pp. 62-68, 1993.

[6] B.G. Shen, F.W. Wang, L.S. Kong, L. Cao, and W.S. Zhan, "A Novel Hard Magnetic Material for Sintering Permanent Magnets," J. Appl. Phys., Vol. 75, pp. 62536255, 1994.

[7] B.G. Shen, F.W. Wang, L.S. Kong, L. Cao and H.Q. Guo, "Formation and Magnetic Properties of $\mathrm{R}_{2} \mathrm{Fe}_{17}$. ${ }_{x} \mathrm{Ga}_{\mathrm{x}} \mathrm{C}_{2}$ Compounds Prepared by Arc-Melting," J. Magn. Magn. Mater., Vol. 127, pp. L267-272, 1993.

[8] Z. Shan, Y. Liu, Y.S. Jeong, Y.B. Zhang, I.A. Al-Omari and D.J. Sellmyer, "Magnetism of Nanocomposite CoSmBased Films," Proc. of the Third Int. Symp. on Phys. of Magn. Mater., Seoul, Korea, pp. 497-504, 1995 ; J. of Korean Magnetic Society, Vol. 5, pp. 702-709, 1995.

[9] E.M.T. Velu and D.N. Lambeth, "CoSm-Based HighCoercivity Thin Films for Longitudinal Recording," J. Appl. Phys., Vol. 69, pp. 5175-5177, 1991.

[10] T. Yogi, C. Tsang, T.A. Nguyen, K. Ju, L. Gormen and G. Castillo, "Longitudinal Media for $1 \mathrm{~Gb} / \mathrm{in}^{2}$ Area Density," IEEE Trans. Magn., Vol. 26, pp. 2271-2276, 1990 . 